\title{
Insulin-producing cells derived from human pancreatic non-endocrine cell cultures reverse streptozotocin-induced hyperglycaemia in mice
}

Received: 23 November 2004 / Accepted: 27 April 2005 / Published online: 17 August 2005

(C) Springer-Verlag 2005

\begin{abstract}
Aims/hypothesis: The aim of the study was to investigate the potential of human pancreatic non-endocrine cells to transdifferentiate into endocrine cells that would be capable of secreting insulin in response to glucose and ameliorating insulin-deficient diabetes after transplantation. Materials and methods: Cell fractions enriched with exocrine cells after human islet isolation were treated with streptozotocin to remove residual beta cells, grown in monolayer culture to allow de-differentiation, transferred to cluster culture for redifferentiation in the presence of activin A, betacellulin, nicotinamide and glucose, supplemented with $10 \%$ FCS, and administered to streptozotocin-induced diabetic SCID mice. A subset of cells was transfected with the IPF1 gene (also known as PDXI) before transdifferentiation. Results: No insulin was detectable in cell preparations after 5 days of treatment with streptozotocin. In monolayer culture, $90 \%$ of the streptozotocin-treated pancreatic cells co-expressed cytokeratin19 and vimentin at 2 weeks and $60 \%$ expressed nestin at 4 weeks. Cell cultures with a high proportion of nestinexpressing cells had greater plasticity for transdifferentiation into cells with phenotypic and functional markers of beta cells, this property being significantly enhanced by transfection with $I P F 1$ gene and leading to $15 \pm 6.7 \%$ insulin-positive cells after transplantation vs. $0.01 \%$ of cells transplanted after streptozotocin treatment alone. These cells improved glucose control in all of 42 diabetic mice after transplantation, restoring normoglycaemia in
\end{abstract}

M. Zhao · S. A. Amiel · M. R. Christie · G. C. Huang $(\bowtie)$

Department of Diabetes,

Endocrinology and Internal Medicine,

King's College GKT Medical School,

Bessemer Road,

London, SE5 9PJ, UK

e-mail: guo.huang@kcl.ac.uk

Tel.: +44-20-77374000

Fax: +44-20-73463685

M. Rela $\cdot$ N. Heaton

Institutes of Liver Studies,

King's College GKT Medical School,

London, SE5 9PJ, UK
40\%. Conclusions/interpretation: Human pancreatic cells are a potential source of new glucose-responsive insulinproducing cells that may be developed further for clinical use.

Keywords Beta cells · Glucose-responsive - Insulinproducing cells $\cdot$ Pancreatic non-endocrine cells . Transdifferentiation - Transplantation

Abbreviations ABNG: activin A, betacellulin, nicotinamide and glucose - BrdU: 5-bromo-2'deoxyuridine - GLP-1: glucagon-like peptide-1 . Q-PCR: quantitative polymerase chain reaction . STZ: streptozotocin

\section{Introduction}

Pancreatic non-endocrine cells may be a potential source of new beta cells [1-3], as endocrine and exocrine cells in the pancreas share the same developmental origin [4-6]. In culture, endocrine and exocrine cells de-differentiate rapidly and express the same ductal cell marker, CK-19 (human) or CK-20 (rodent) [7-9], indicating that they are de-differentiating in a similar pattern. Furthermore, exocrine and ductal cells of rodents and man have been made to express $\mathrm{Pdx} 1$ protein in vitro $[10,11]$. Pdx 1 is an important transcription factor in pancreatic development and maintenance of the beta cell phenotype [12], and its presence suggests that the exocrine and ductal cells can transdifferentiate into cells with the potential to become endocrine cells and that cells with the ductal phenotype may be an intermediate product between undifferentiated and differentiated cells. Human pancreatic duct cells have been implicated as the origin of new beta cells in systems, without $[13,14]$ and with [15] the help of ectopic gene expression. Rodent exocrine cells can express insulin [16], supporting the concept that the exocrine cell may be a candidate for new beta cells. However, the goal of generating glucose-responsive beta-cell surrogates in numbers sufficient to reverse diabetes remains elusive and ultimately a human cell source will be required 
for clinical purposes. In an attempt to enhance the efficacy of beta cell generation from human sources, we first extended the culture of the non-endocrine cells to induce partial dedifferentiation. We then introduced redifferentiation in these cells by culturing them in an environment that favoured differentiation of endocrine cells in vitro, with or without prior ectopic expression of IPF1 (also known as $P D X 1$ ). Finally, we allowed the partially differentiated cells to mature in a diabetic environment in vivo before assessing their ability to correct hyperglycaemia in diabetic mice.

\section{Materials and methods}

\section{Reagents}

Monoclonal antibody to human insulin (I2018), rabbit antihuman $\alpha$-amylase antiserum (A8273), glucagon-like peptide-1 (GLP-1) (G3265) and nicotinamide were purchased from Sigma (Sigma-Aldrich, Poole, Dorset, UK). Anticytokeratin-19 (Sc-6278) monoclonal antibody and antineuroD (Sc-1084) were purchased from Santa Cruz (Santa Cruz Biotechnology, Heidelberg, Germany). Monoclonal antibody against human fibroblast (clone 5B5) and rabbit anti-human Ki-67 antigen antiserum were obtained from Dako (Glostrup, Denmark). Anti-nestin monoclonal antibody (MAB 5326) was purchased from Chemicom International (Temecula, CA, USA). Human-specific vimentin monoclonal antibody (clone V9, Non3005) was purchased from Monosan (Amsterdam, The Netherlands). Recombinant human betacellulin and activin A proteins were from R\&D Systems (Oxford, UK).

\section{Culture of human pancreatic non-endocrine cells}

Human pancreases were obtained with permission from the local hospital ethical committee and informed consent from families of organ donors $(n=16$, seven male, nine female; age 18-58 years). Cold ischaemia time was $5.2 \pm 1.5 \mathrm{~h}$ (mean $\pm \mathrm{SD}$ ). The pancreases were subjected to liberase digestion and density gradient fractionation as previously described [17]. Gradient fractions enriched with exocrine cells were collected, washed twice with Hanks' balanced salt solution and cultured in suspension as clusters [18] in CMRL1066 medium (Invitrogen, Inchinnan, UK), supplemented with $10 \%$ FCS and $0.95 \mathrm{mmol} / \mathrm{l}$ freshly prepared streptozotocin (STZ; Sigma) at $37^{\circ} \mathrm{C}$ in a humid $5 \%$ carbon dioxide incubator for 5 days, with medium and STZ changed daily to remove contaminating beta cells and dead cells. Cell samples were collected daily for genomic DNA preparation (Promega, Southampton, UK) to determine cell number indirectly, and for analysis of insulin content by immunocytochemical staining, RIA and RT-PCR as previously described $[17,18]$. After STZ treatment, the cells were cultured as monolayers. They were seeded at $3 \times 10^{6}$ cells $/ 10 \mathrm{~cm}$ Petri dish and grown initially at approximately $70 \%$ confluence in CMRL1066 medium with $55 \mu \mathrm{mol} / 1$ G418 to inhibit the growth of fibroblasts [9] for up to 7 weeks. Cell samples were analysed at intervals of 5-7 days by immunocytochemistry and RT-PCR [18] to assess phenotypic changes. Quantitative PCR (Q-PCR) was used to confirm key RT-PCR experiments and analysed using published methods $[19,20]$.

\section{Analysis of cell proliferation}

Cells from the monolayer cultures were dissociated using trypsin/EDTA and counted at intervals. Cell division was assessed using a 5-bromo-2'-deoxyuridine (BrdU) incorporation assay. For this, cells were seeded $2 \mathrm{~h}$ earlier, $65 \mathrm{nmol} / \mathrm{l} \mathrm{BrdU}$ was added, and culture continued for $16 \mathrm{~h}$. The cells were washed and dissociated and centrifuged to form a pellet. The pellet was cryosectioned and stained for both BrdU and Ki67, an endogenous proliferation marker $[21,22]$, using published methods [18].

\section{Human IPF1 expression plasmid and transfection}

The coding region of the human IPF1 gene was amplified by PCR using a primer set (Table 1). The cDNA was cloned into the expression plasmid pIRES-N1 [23] and partially sequenced. DNA transfections were performed using lipofectamine 2000 (Invitrogen) according to the manufacturer's instructions. Plasmid carrying the $\beta$-galactosidase reporter gene (pCMV $\beta$; BD Biosciences, San Jose, CA, USA) was used to establish optimal transfection conditions, and approximately 30\% efficiency was achieved. Briefly, $4 \times 10^{6}$ cells $/ 10 \mathrm{~cm}$ Petri dish were seeded $3 \mathrm{~h}$ before transfection. Plasmid DNA $(16 \mu \mathrm{g})$ was diluted in $1.5 \mathrm{ml}$ of OptiMEM medium (Invitrogen) in tube A and $60 \mu \mathrm{l}$ of lipofectamine 2000 was diluted with $1.5 \mathrm{ml}$ of OptiMEM medium in tube B. Following incubation at room temperature for $5 \mathrm{~min}$, DNA in tube A was mixed with the lipofectamine 2000 in tube B and incubation was continued at room temperature for another $20 \mathrm{~min}$. Before transfection, the cells were rinsed once with OptiMEM medium and $3 \mathrm{ml} \mathrm{DNA} /$ lipofectamine 2000 mixture was added drop-wise onto the cells. The cells were incubated at $37^{\circ} \mathrm{C}$ in a humid $5 \%$ carbon dioxide incubator for $3 \mathrm{~h}$. The transfection mixture was then removed and rinsed once with culture medium, and cultured for another $48 \mathrm{~h}$. The cells were dissociated using trypsin/EDTA and converted into cluster culture [18]. Empty plasmid pIRES-N1 was used as a negative transfection control.

\section{Transdifferentiation induction}

To induce the partially de-differentiated non-endocrine cells into low-degree differentiation in vitro, the 4-week monolayer-cultured cells were converted to cluster culture in CMRL1066 overnight [18]. Next morning, the medium was replaced with serum-free CMRL1066 containing $50 \mathrm{nmol} / 1 \mathrm{GLP}-1$ (Sigma-Aldrich) and incubated for $3 \mathrm{~h}$. Then, a cocktail of differentiation inducers was added at 
final concentrations of $25 \mathrm{pmol} / \mathrm{l}$ activin A, $200 \mathrm{pmol} / 1$ betacellulin, $10 \mathrm{mmol} / \mathrm{l}$ nicotinamide and $16.5 \mathrm{mmol} / \mathrm{l}$ glucose (ABNG; added only in cluster culture), supplemented with $10 \%$ FCS. The cells were cultured for additional 4-10 days, with medium and ABNG replaced every 2 days. Cell samples were taken and assessed for expression of beta cell markers.

\section{Semi-quantitative RT-PCR}

Total RNA was isolated using an RNA Miniprep Kit (Promega) and quantified using a spectrometer (Gene Quant II; Pharmacia Biotech, Cambridge, UK) at $260 \mathrm{~nm}$ wavelength [18]. Briefly, $100 \mathrm{ng}$ of total RNA was converted into first-strand cDNA using reverse transcriptase (Invitrogen) in a volume of $20 \mu \mathrm{l}$. The hot-start (Qiagen, Crawley, UK) RT-PCR was used with the following parameters: $95^{\circ} \mathrm{C}$ for $15 \mathrm{~min}$ for one cycle; then 25 cycles of PCR with Ipfl, 28 cycles with NeuroD1 and preproinsulin unless specified otherwise, and 30 cycles with $S L C 2 A 2$ (also known as GLUT-2) and glucokinase, while $\beta$-actin was amplified in parallel for 21 cycles as an internal control using the primers listed in Table 1. The relative quantity of DNA was analysed using a gel program (version 3.0 computer analyser of Media Cybernetics, Silver Spring, MD, USA) and expressed relative to the density of $\beta$-actin gene PCR product.

\section{Quantitative PCR}

Q-PCR was performed with the LightCycler-2 (Roche Diagnostics, Lewes, UK) using the SYBR Green I fluorescence kit (Roche Diagnostics) and was mainly used to confirm the key semiquantitative RT-PCR. Target genes, such as human preproinsulin (435 bp), NeuroD1 (410 bp), IPF1 (508 bp), SLC2A2 (523 bp) and glucokinase (597 bp), and the reference gene human $\beta$-actin (664 bp) were amplified in duplicate and cDNA from at least three donors was tested for each set of experiments. PCR was amplified in
$20 \mu \mathrm{l}$ with $0.25 \mu \mathrm{mol} / 1$ primers and appropriate amounts of DNA template. PCR-grade water was used as a negative control. Amplification efficiency was assessed by using a series of $10 \times$ dilutions of plasmid containing the gene or dilutions of cDNA templates. After an initial 15-min preincubation step at $95^{\circ} \mathrm{C}$, the following parameters were used: $95^{\circ} \mathrm{C}$ for $10 \mathrm{~s}, 53-58^{\circ} \mathrm{C}$ for $20 \mathrm{~s}$ and $72^{\circ} \mathrm{C}$ for $45 \mathrm{~s}$ for 40 cycles. The relative copy number was corrected to 10,000 copies of human $\beta$-actin mRNA and expressed as copy number per 10,000 copies of $\beta$-actin gene $\pm S D$, using the comparative threshold $\left(C_{\mathrm{t}}\right)$ method $[19,20]: 2^{-\Delta \mathrm{Ct}}$ where $\Delta C_{\mathrm{t}}=\left(C_{\mathrm{t}}\right.$ of the target gene minus $C_{\mathrm{t}}$ of the reference gene). The $C_{\mathrm{t}}$ of the genes was determined using thermocycler software (version 3.5; Roche Diagnostics).

Immunochemical staining

The methods used have been described previously [18]. Briefly, cultured cells or tissues were mounted with OCT compound (Merck, Lutterworth, Leics, UK) and cryosectioned at $5 \mu \mathrm{m}$ intervals. The sections were assessed for the presence of specific antigens by peroxidase-based immunocytochemical staining (Vector Laboratories, Peterborough, UK). The primary antibody was replaced with speciesrelated normal serum to validate specific staining. To visualise the antigens, VIP (violet) substrate (Vector Laboratories) was used. At least 5000 cells per sample were counted.

Animals and surgical procedures

Male SCID mice (20-25 g, C.B-17/Icr), purchased from Charles River Laboratories, Margate, UK, were selected as recipients for transplantation and were maintained in filter cages in the Comparative Biology Centre at King's College London, according to guidelines of the Home Office (UK) for Animal Scientific Procedures. Diabetes was induced by a single injection of STZ (180 mg/kg i.p.) and confirmed by
Table 1 PCR primer sets

IPF1 cloning forward primer
IPF1 cloning reverse primer
IPF1 PCR forward primer
IPF1 PCR reverse primer
Preproinsulin forward primer
Preproinsulin reverse primer
NeuroD1 forward primer
NeuroD1 reverse primer
SLC2A2 forward primer
SLC2A2 reverse primer
Glucokinase forward primer
Glucokinase reverse primer
Nestin forward primer
Nestin reverse primer
Human $\beta$-actin forward primer
Human $\beta$-actin reverse primer

IPF1 cloning forward primer prime IPF1 PCR reverse primer Preproinsulin forward primer Preproinsulin reverse primer NeuroD1 forward primer NeuroD1 reverse primer $S L C 2 A 2$ forward primer $S L C 2 A 2$ reverse primer Glucokinase forward primer Nestin forward primer Nestin reverse primer Human $\beta$-actin reverse primer

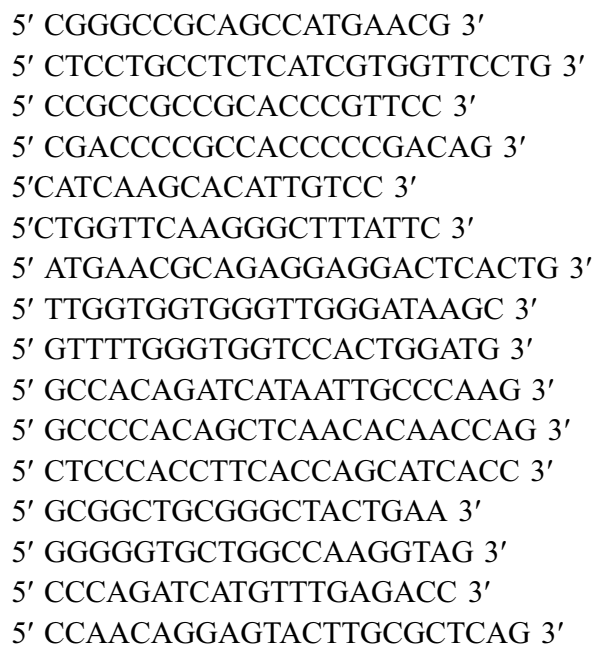


the presence of hyperglycaemia. The diabetic condition was allowed to stabilise for 7-10 days before transplantation. The diabetic mice were randomly allocated to a transplant recipient group and a sham-operated control group. The surgical procedures have been described [18]. Briefly, under anaesthesia, a median lateral laparotomy was performed and the left kidney was exposed. Approximately 1500 cell clusters (approximately $2.5 \times 10^{6}$ cells) in a volume of $50 \mu \mathrm{l}$ were transplanted into the kidney parenchyma tissue by direct insertion of a Hamilton syringe into the kidney at the lower pole, crossing the kidney and reaching the capsule membrane. The cells were discharged into the parenchyma as the syringe was slowly withdrawn. In the sham control group, a cell-free saline injection was made in exactly the same way. Plasma glucose was measured using a G2 blood glucose sensor from MediSense (Abbott Laboratories, Dublin, Ireland).

Intraperitoneal glucose tolerance test

The mice were fasted overnight and the plasma glucose level was determined. A glucose solution at $1.5 \mathrm{~g} / \mathrm{kg}$ body weight was injected intraperitoneally and plasma glucose levels were determined 30, 60, 90, 120 and 180 min after injection.

At the end of the experiments, blood, kidneys and pancreases were removed. Immunohistochemistry was performed on the tissues for markers of endocrine, exocrine cells, ductal cells, fibroblasts, and vimentin- and Ki67expressing cells. Cell nuclei were counterstained with propidium iodide (Sigma-Aldrich) and analysed by fluorescence or confocal microscopy. Cells that stained positive and the total number of transplanted cells (total grafted cells) were counted under light fluorescence microscopy and the percentage of positive cells was derived by counting a total of 1500 graft cells per staining. The concentration of human-specific C-peptide was determined by RIA (DSL, Webster, TX, USA). Organs from sham-operated mice were studied in parallel as a negative control.

\section{Data analysis}

All data are expressed as mean \pm SD unless specified otherwise and statistical differences between groups were determined by ANOVA (Microsoft Excel, Office 2000). Differences between groups were considered significant when $p<0.05$.

\section{Results}

Removal of beta cells from human pancreatic non-endocrine cell preparations

Under light microscopy, the exocrine-cell-enriched cell fractions contained $<0.3 \%$ insulin-positive cells (Fig. 1a) by dithizone staining. Following STZ treatment, beta cells were not detectable by dithizone staining $(n=16)$ or by antiinsulin immunocytochemical staining $(n=5$, data not shown). The cells were predominantly exocrine cells $(79 \pm 12 \%$ amylase-positive) and ductal cells $(15 \pm 11 \%$ cytokeratin19-positive, $n=16$ ). The expression of preproinsulin mRNA $(n=5)$ was significantly reduced, as determined by semiquantitative RT-PCR (Fig. 1b) following STZ treatment, consistent with the data from the Q-PCR. The number of copies of preproinsulin mRNA/10,000 copies of human $\beta$-actin mRNA was reduced from 40 to 3.5 following STZ treatment, a ten-fold decrease (Fig. 1c; $n=4, p<0.01)$. Insulin protein was not detectable by RIA [18] (Fig. 1d; $n=5$ ). Cell death occurred during STZ treatment and the cell mass was reduced by $20 \%$, as assessed by the reduction of genomic DNA (Fig. 1e; $n=4$ ). In a further confirmation of the removal of beta cells, STZtreated cells were implanted in the kidneys of the STZinduced diabetic SCID mice. Fewer than $0.01 \%$ of graft cells were subsequently found to be positive for insulin (Fig. 1f, $n=4$ ), a 30 -fold decrease in beta-cell number, confirming the removal of most beta cells by the isolation procedure and STZ treatment.

\section{Expression of transient markers}

During 7 weeks of monolayer culture at $\sim 70 \%$ confluence, there was a rapid decrease in amylase-positive cells. The cell proliferation rate was low until 3 weeks in culture, as determined by the proliferation marker Ki67, BrdU incorporation and cell counting (Fig. 2a). As the initial proliferation rate was low (Fig. 2a), the cell number at day 7 was used as the starting cell number. The cell number decreased to $80 \%$ after the first trypsinisation. After the second week in culture, most cells adapted to the culture conditions and appeared healthy, with no microscopic evidence of cell death. Compared with the cell number at 7 days, the fold change in cell number by the end of the second, third and fourth weeks was $0.81 \pm 0.03,1.18 \pm 0.03$ and $1.45 \pm 0.055(n=4)$, respectively. The percentage of fibroblast cells in the initial cell preparations was $<1 \%$ and there was no evidence of rapid proliferation, as there were fewer than $10 \%$ fibroblast cells during the 4 -week cultures (Fig. 2a). The cells underwent rapid transdifferentiation in vitro. Expression of CK19 increased transiently, with a maximum of $90 \%$ of cells expressing CK19 after 2 weeks (Fig. 2a), declining thereafter. The cells expressing CK19 were not the typical duct cells as most of the $\mathrm{CK} 19^{+}$cells also co-expressed vimentin, a marker of mesenchymal cells. Vimentin was not expressed in duct cells in human pancreas tissues (data not shown). Vimentin-expressing cells increased from 3\% in the cell preparations to $95 \%$ after 2 weeks in monolayer culture (Fig. 2a). The number of CK19-expressing cells decreased rapidly, while vimentin-expressing cells declined relatively slowly and there were still more than $50 \%$ of vimentin-expressing cells by 4 weeks (Fig. 2a). Nestin expression (absent from the initial 
a

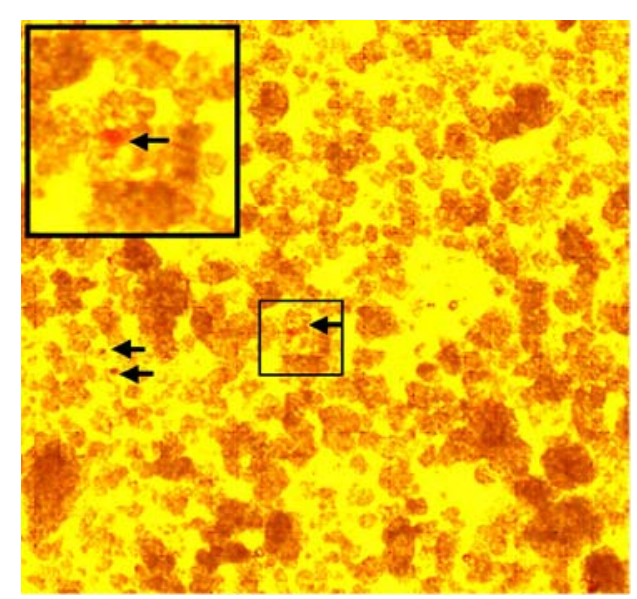

C
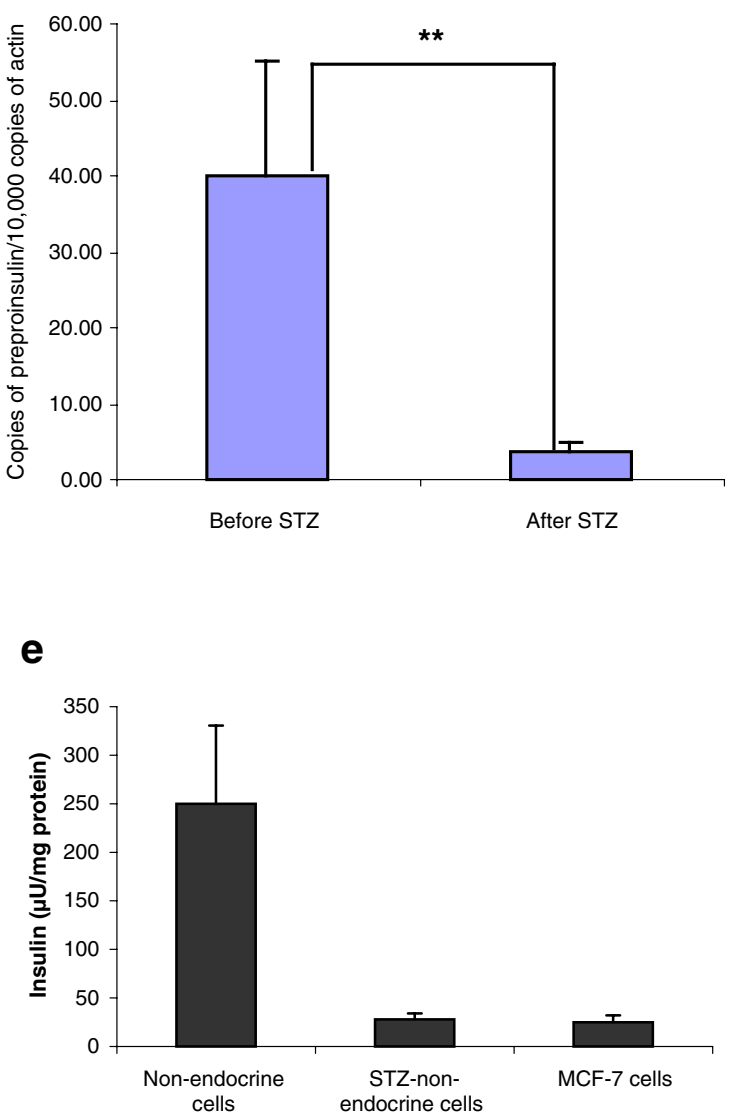

Fig. 1 Removal of beta cells from exocrine cell preparations. a Typical low-power microscopic image of a routine preparation of human exocrine-cell-enriched cells following dithizone staining, showing the presence of $<0.3 \%$ of dithizone-positive cells (arrows), with boxed area enlarged (inset). b Semiquantitative RT-PCR showing reduction in expression of preproinsulin in the cells following streptozotocin (STZ) treatment. c. Relative quantitative RT-PCR, confirming the reduction in expression of preproinsulin in exocrine cell preparation following STZ treatment $(n=12) ; * * p<0.01$. d Reduction of genomic DNA during STZ b
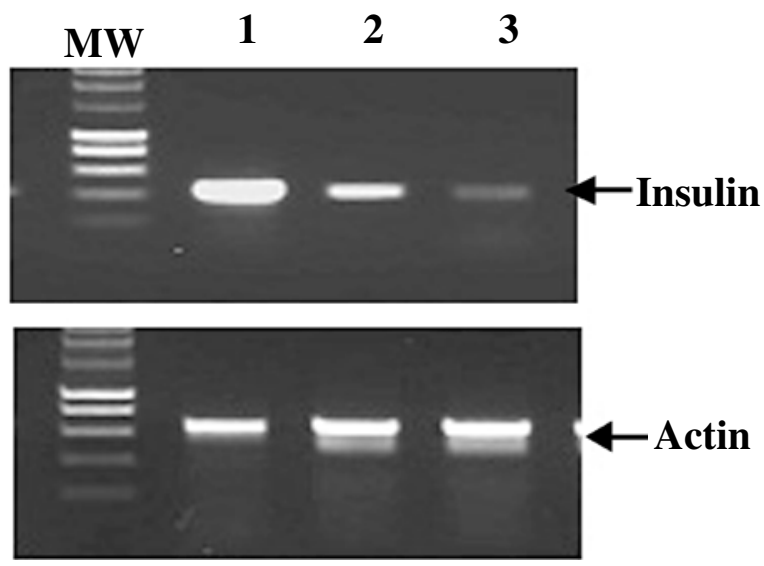

d

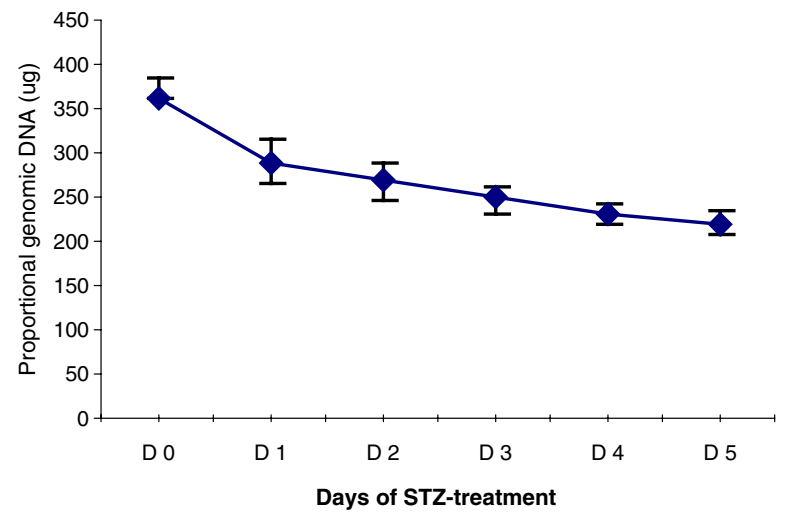

$\mathbf{f}$

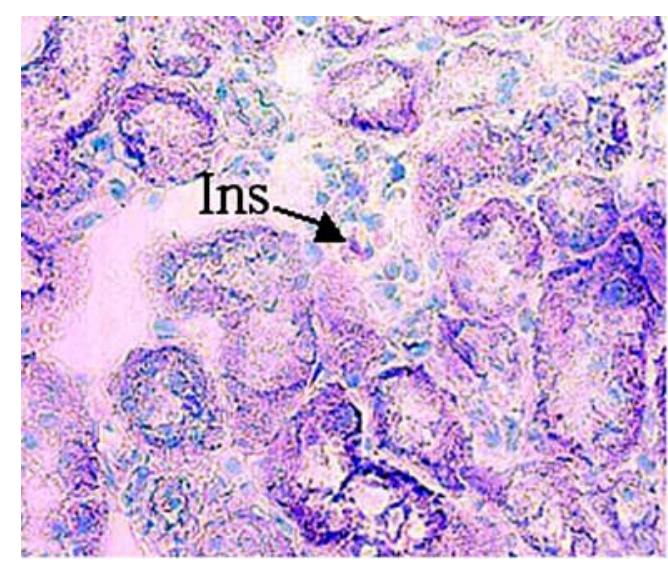

treatment, indicating that cell loss is more obvious during the initial period of STZ treatment $(n=4)$. e Insulin content in the cells after STZ treatment, showing no difference from the lysate of MCF-7, a cancer cell line that does not express insulin. $\mathbf{f}$ Typical microscopic image of a graft of STZ-treated cells 6 weeks after transplantation within the kidney of an SCID mouse. It shows $<0.01 \%$ cells positive for insulin (violet, arrow; nuclei counterstained with methyl green), which is a 30 -fold decrease in beta cells compared with untreated cells (a), indicating that STZ treatment removed most beta cells 
Fig. 2 Phenotypic changes in cells cultured in monolayers for up to 49 days. a Phenotype changes during culture. Incorporation of amylase (yellow, $n=8$ ); CK19 (dark blue, $n=8$ ), nestin (pink, $n=8$ ), fibroblasts (green, $n=4$ ), vimentin (midblue, $n=6$ ), Ki67 (light blue, $n=5$ ) and BrdU (purple, $n=5$ ), assessed by immunocytochemical staining and cell number changes (brown, $n=6$ ) by counting. b Expression of nestin mRNA analysed by RT-PCR of cells maintained in monolayer culture

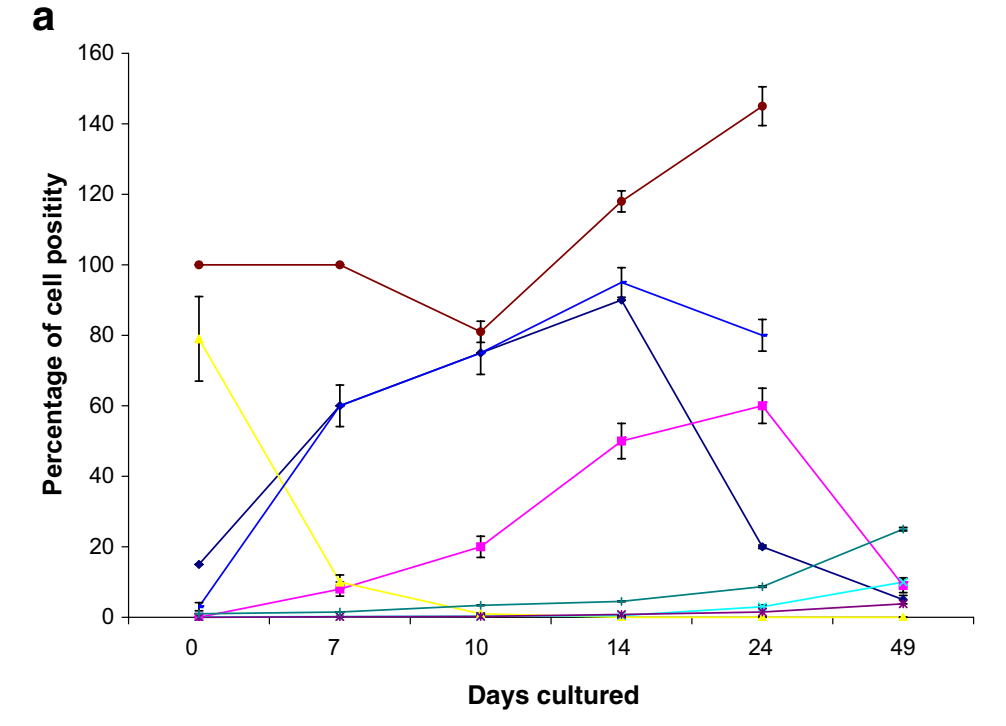

b

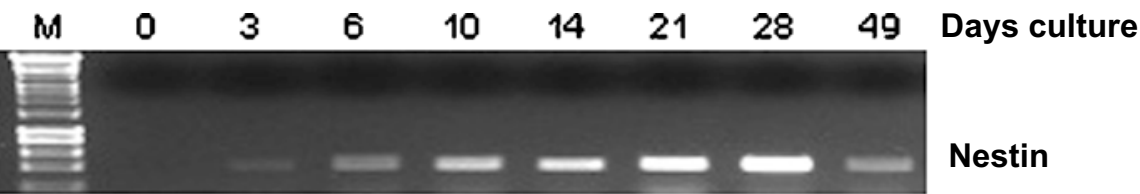

a

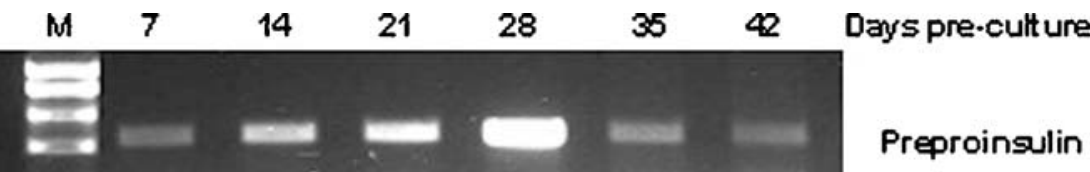
culture for 8 days in the pres-
ence of ABNG differentiation inducers. b Beta cell marker
analysis of cells precultured fo inducers. b Beta cell marker
analysis of cells precultured for 28 days in monolayer and subsequently cultured as clusters for 8 days in the absence $(-)$ or presence $(+)$ of differentiation factors of ABNG. c Relative quantitative RT-PCR confirming changes in expression after induction of differentiation

the expression of preproinsulin and actin mRNA from cells that had been reverted to cluster that had been reverted to cluster

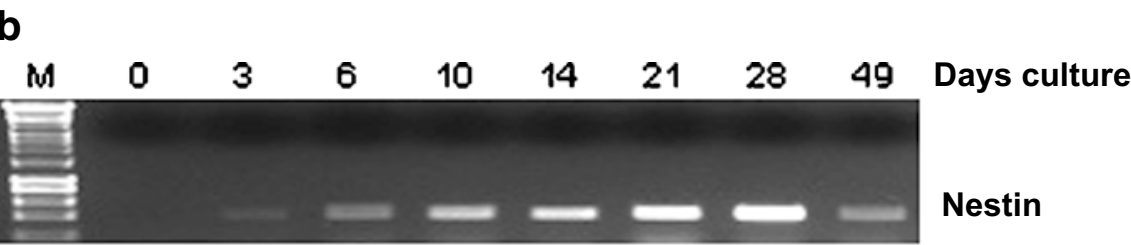

b
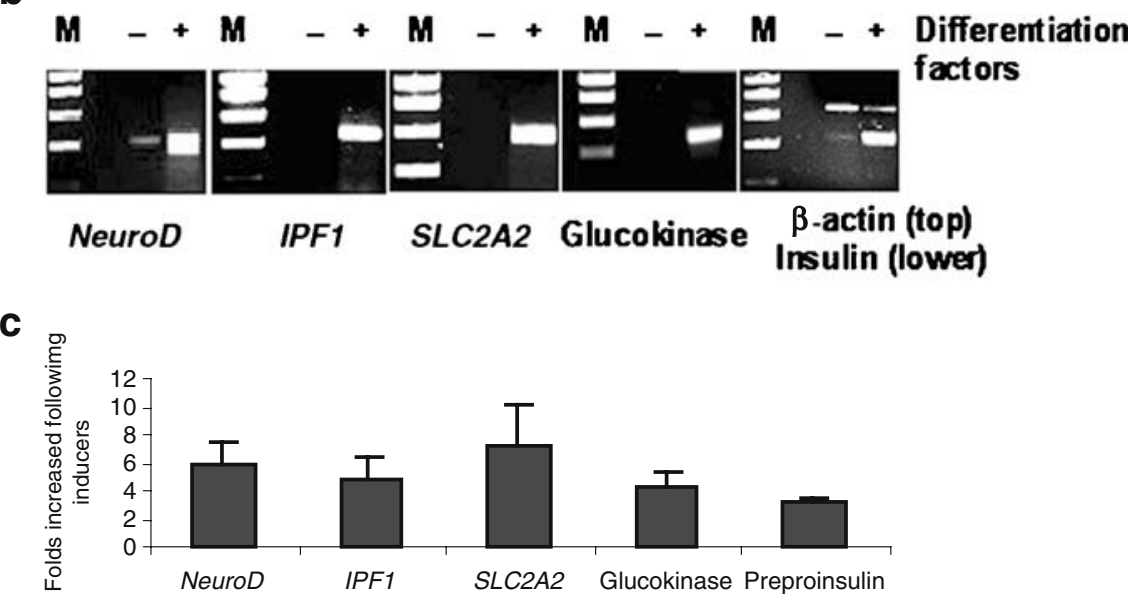
cell preparations) was first detected after 3 days of culture and increased to $60 \%$ after 4 weeks of culture, declining thereafter (Fig. 2a). The expression of nestin protein was simultaneous with its mRNA expression (Fig. 2b).

\section{Plasticity of pancreatic non-endocrine cells}

Cells in monolayer culture, without a phase of differentiation induction, did not express any mRNA specific for beta cells. We examined the existence of plasticity in the monolayer-cultured cells at various time points by converting them to cluster culture in the presence of differentiation inducers. After cluster culture with the differentiation cocktail ABNG, preproinsulin mRNA was detected in the cells, with maximal expression (Fig. 3a) in the cells following 4 weeks of monolayer culture, coincident with the highest percentage of cells expressing nestin protein (Fig. 2a). These cells also expressed other phenotypic markers of beta cells, including the products of NeuroD1, $I P F 1, S L C 2 A 2$ and glucokinase (Fig. 3b), confirmed by relative quantitative RT-PCR analyses (Fig. $3 \mathrm{c}, n=4$ ). The best effect was seen after 8 days' incubation with ABNG. However, insulin protein was not detected. After transplanting these cells into diabetic SCID mice, a small percentage $(3 \pm 2.3 \%, n=6)$ of insulin-producing cells was detected by immunohistochemistry 6 weeks later, but there was no significant reduction in hyperglycaemia in the mice (data not shown).

\section{Effect of transfection with $I P F 1$}

The cells that had been cultured for 4 weeks were transfected with $I P F 1$ for $48 \mathrm{~h}$ and then converted to cluster culture for 8 days in the presence of ABNG as described above. Q-PCR showed a $2.15 \pm 0.21$ - and $3 \pm 0.5$-fold increase in the expression of preproinsulin and NeuroD1 mRNA, respectively in the IPF1-transfected cells compared with the vector control cells (Fig. 4, $n=6$ ). SLC2A2 and glucokinase did not show significant changes (data not shown). Again, despite the increased expression of preproinsulin mRNA, the cells did not contain detectable insulin protein ( $n=6$, data not shown).
Effect of transplantation into STZ-induced diabetic mice

All of the 42 mice that received cells transfected with IPFI prior to incubation with $A B N G$ showed a progressive reduction in plasma glucose concentrations over a period of 6 weeks (Fig. 5a). Forty per cent of the mice achieved nonfasting blood glucose levels within the non-diabetic range $(<9 \mathrm{mmol} / \mathrm{l})$ and all of these showed measurable human Cpeptide in their sera, as described below. In contrast, mice transplanted with cells transfected with empty vector remained hyperglycaemic, as did sham-operated mice and mice transplanted with cells isolated from the original STZtreated pancreatic cells (Fig. 5a). Figure 5b shows the results of intraperitoneal glucose tolerance testing in six of 17 mice that had regained normoglycaemia after implantation with IPF1 transfected cells, together with four shamoperated mice and four normal mice. The active implantation restored glucose tolerance to a near-normal level. The fasted human C-peptide value in mice that had regained normoglycaemia was $0.63 \pm 0.31 \mathrm{ng} / \mathrm{ml}(n=11)$ and $1.05 \pm$ $0.25 \mathrm{ng} / \mathrm{ml}(n=6)$ following the intraperitoneal glucose tolerance test, indicative of graft function, while humanspecific C-peptide was undetectable in sham-operated and normal mice. Immunohistochemical analysis of kidney sections of the mice that had returned to normoglycaemia showed healthy grafts that contained $15 \pm 6.7 \%$ insulinpositive cells (Fig. 5c), $8 \pm 2.3 \%$ glucagon-positive cells (Fig. $5 \mathrm{~d}$ ) and $3 \pm 085 \%$ somatostatin-positive cells (Fig. 5e). The grafts of the mice transplanted with vector-transfected cells contained $3 \pm 1.85 \%$ insulin-positive cells (Fig. 5f; $n=6$ ), similar to those without IPF1 transfected cells (data not shown). There were no amylase-positive cells in the grafts, while $4 \pm 0.85 \%$ fibroblasts, $2.5 \pm 0.5 \%$ CK 19 -positive cells and $15.6 \pm 3.5 \%$ vimentin-positive cells were observed in the grafts. No gross tumour formation was seen in the animals and no tumour-like structures were observed among the grafts. Only $1.5 \pm 0.5 \%(n=8) \mathrm{Ki}^{+} 7^{+}$cells were found in the grafts, suggesting no significant cell proliferation in the grafts. Approximately 50\% grafted cells were unidentifiable with the antibodies used. The pancreases of all STZ-treated groups showed numerous sites of damaged islets and only a few residual beta cells (Fig. $5 \mathrm{~g} ; n=6$ ) remained, with no significant differences between trans-
Fig. 4 RT-PCR analysis of the expression of preproinsulin, IPF1 and NeuroD1 in cells precultured for 28 days in monolayer and subsequently transfected with IPFI (lanes 1) or the empty vector (lanes 2 ) after treatment with differentiation factors for 8 days, corrected to the expression of $\beta$-actin. The RT-PCR was amplified for 22 cycles in order to distinguish the differential expression level

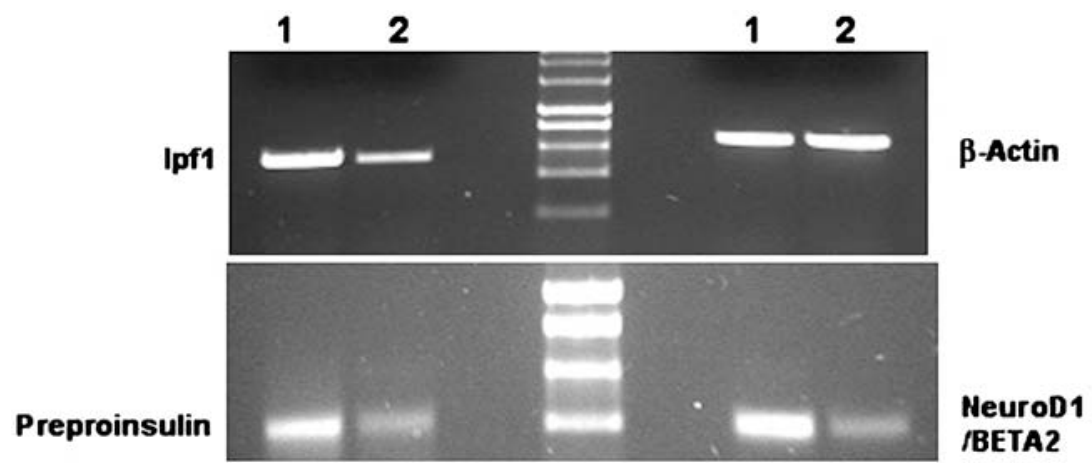


a

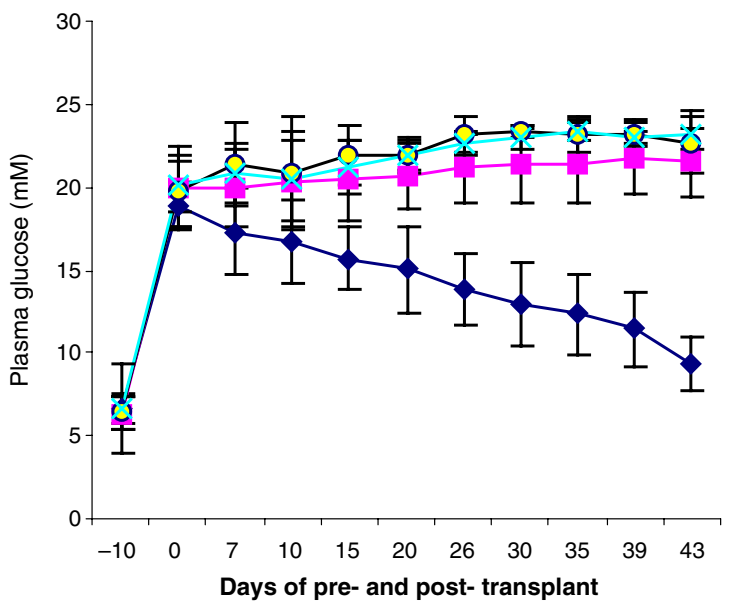

b

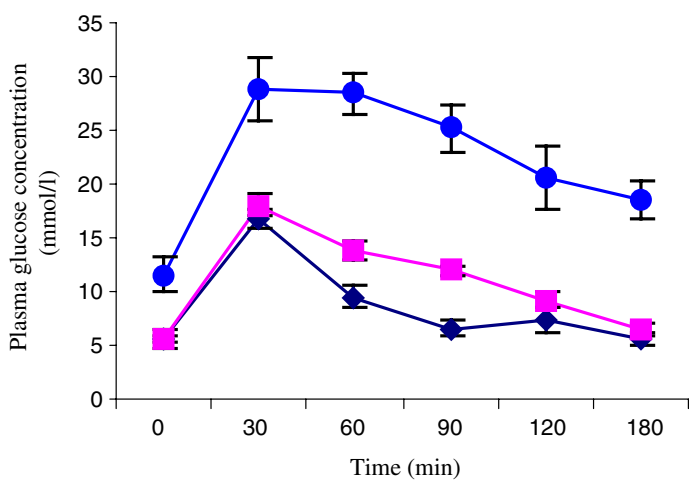

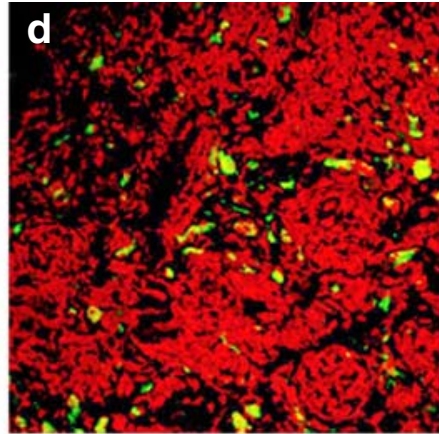
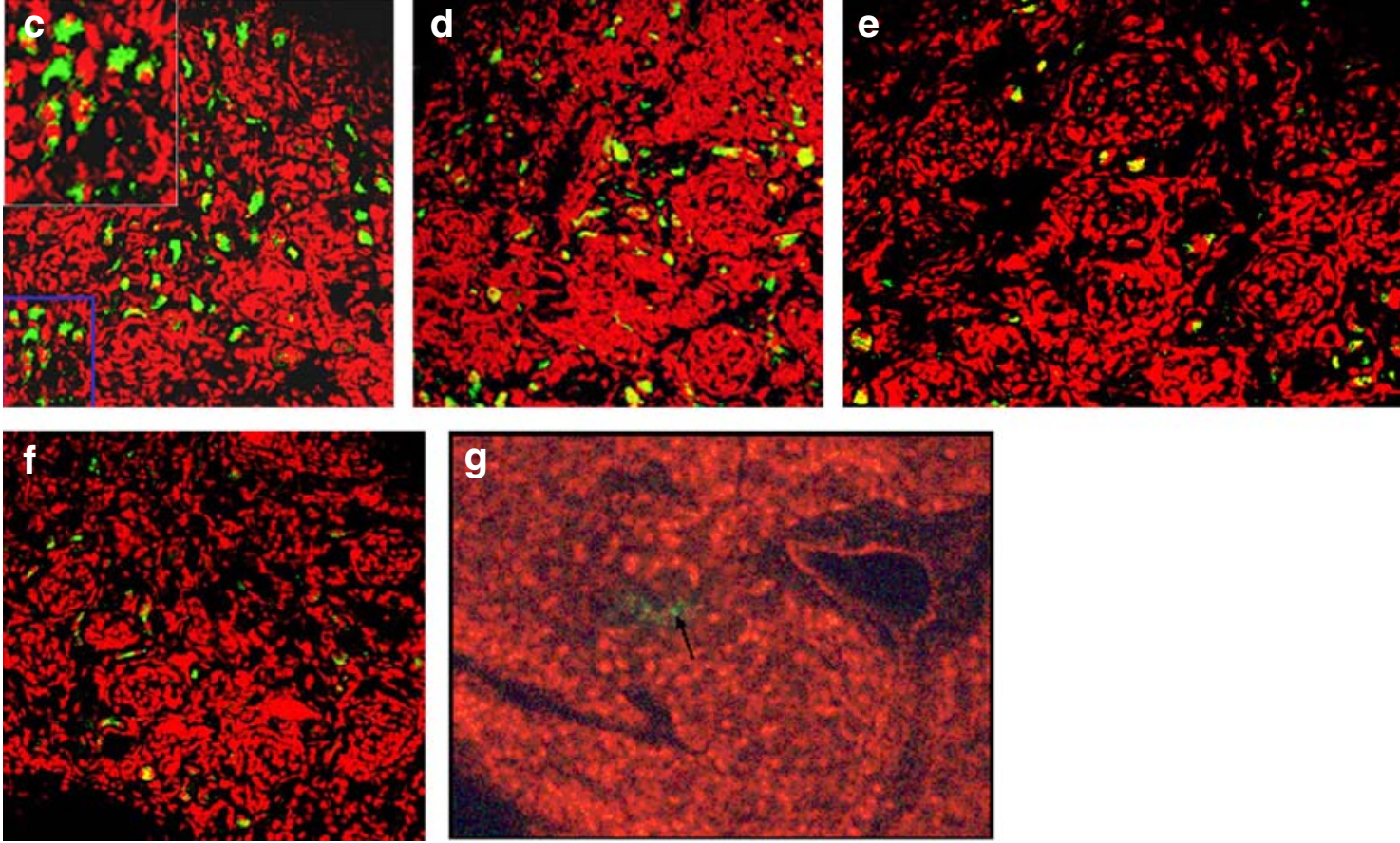

Fig. 5 a Non-fasted plasma glucose level over time in SCID mice rendered diabetic with STZ. Values are shown from 10 days before and after transplantation, either with IPF1 $(n=42)$, or with empty vector-transfected-cells (pink, $n=12$ ) treated with differentiation factors as in Fig. 3b and Fig. 4, and cells that had received 5 days of STZ treatment (light blue, $n=4$ ). Sham-operated mice (yellow, $n=8$ ) were used as controls. b. Intraperitoneal glucose tolerance tests on the $6 / 17$ mice that regained normoglycaemia (pink, $n=6$ ) with diabetic mice (mid-blue, $n=4$ ) and normal mice (dark blue, $n=4$ ) as control. c-e The typical immunohistochemical images (green fluores-

planted and sham-operated groups. There was no evidence of beta-cell proliferation (Ki67-positive cells) in the pancreatic islets (data not shown).

\section{Discussion}

In this study, we explored the potential of human pancreatic non-endocrine cells from normal human pancreas donors cence) of kidney grafts of STZ-induced diabetic SCID mice 6 weeks after transplantation with IPF1 gene-transfected human pancreatic nonendocrine cells and stained for insulin (c), glucagon (d) or somatostatin (e) in mice that had regained normoglycaemia, in comparison with insulin-expressing cells (green fluorescence) derived from cells that had been transfected with empty vector (f). Insulin-positive cells (c) are boxed and enlarged (inset). g. Typical section of pancreas of STZinduced diabetic SCID mouse that had regained normoglycaemia, showing residual beta cells (green fluorescence, arrow) in the damaged islets (arrowhead). The nuclei are counterstained with propidium iodide

as a source of glucose-responsive insulin-producing cells. We developed a three-step protocol: (1) in vitro partial dedifferentiation of pancreatic non-endocrine cells; (2) ectopic expression of IPF1 in the partially de-differentiated cells followed by differentiation induction in vitro; and (3) transplantation to allow further differentiation into mature insulin-producing cells in vivo. This protocol produced cells that reversed moderate hyperglycaemia in $40 \%$ of diabetic mice and improved glucose control in the re- 
maining $60 \%$. It should be noted that the organ donors covered a broad range of ages and both genders.

The source material for this study was human pancreas donated for islet isolation. To prove the principle, it was important to remove pre-existing beta cells from the cell preparations, thereby ensuring that the insulin-producing cells identified were newly developed. The first step was to take the cell fractions from the pancreatic digests that were depleted of islets. There were no effective ways to remove human beta cells from the cell preparations. Therefore, the cell preparations were treated with STZ, an effective betacell toxin in rodents. Human beta cells are relatively resistant to STZ [24]. Nevertheless, STZ has been successfully used in combination with other drugs in treating tumours of beta-cell origin in man [25-27], although betacell tumours may react to STZ differently from non-tumour cells. We used a high concentration of STZ $(0.95 \mathrm{mmol} / \mathrm{l})$, a concentration that is lethal to mice, in four consecutive treatments. This removed all dithizone-positive cells from our preparations. It remains possible that endocrine cells in the final transplants may have come from undetected residual beta cells, but the numbers make this unlikely. Even after transplantation of the STZ-treated cells, a mere $0.01 \%$ of cells were insulin positive and the mice remained hyperglycaemic (Fig. 5a), making it unlikely that the $15.6 \%$ insulin-producing cells identified in the fully redifferentiated transplanted cells were carryover beta cells.

Nestin, observed in our de-differentiated cells, is an intermediate filament protein originally described as a neuronal stem cell marker [28]. The association of nestin with pancreatic endocrine cells is not clear [29-32]. The conversion of mouse embryonic stem cells to insulin-secreting cells in vitro involves an intermediate stage when nestin is expressed [33]. It is thought that the expression of nestin may be a marker of a transient cell state intermediate between differentiated and undifferentiated. In addition, we observed that when cell cultures contained a high proportion of nestin-expressing cells, the cells showed a greater capacity to express markers of beta cells following differentiation induction. Therefore, the expression of nestin was taken as a phenotypic marker for transdifferentiation induction in this study.

The molecular mechanisms underlying the transdifferentiation are not clear. We speculate that during culture the non-endocrine cells change their differentiation status and may gain some transient elements, yet to be identified, that allow them to respond better to differentiation induction. The ability to express beta cell markers was closely related to the length of time cells were in monolayer culture, supporting this hypothesis. The transient expression of duct-cell marker is interesting, as cells with duct-cell phenotype have been shown to be capable of expressing markers of beta cells in vitro without $[13,14]$ or with the ectopic expression of NEUROG3 [15]. More interestingly, the CK19-positive cells in this system were not typical duct cells as they also co-expressed vimentin, a marker of mesenchymal cells, probably connected with epithelial-tomesenchymal transition [34]. As mention earlier, Pdx-1 is one of the most important transcription factors determining pancreatic development and maintenance of the beta-cell phenotype [12, 35-37]. More importantly, forcing the expression of IpfI in liver cells in diabetic mice induces the expression of insulin [38], converting the liver into a pancreas in Xenopus tadpoles [39] and hepatocytes to cells with phenotypes of pancreatic cell in mice [40]. Ipf1 has also been shown to facilitate the expression of insulin in liver cells in mice with damaged islets when their liver cells are undergoing active regeneration [41]. Together with the differentiation inducers, $\mathrm{Pdx}-1$ seems to play a synergistic role in forcing cells with transient plasticity into low-level differentiation towards endocrine cells by functioning as a switch [42], driving a change in the gene expression profile of cells. For example, the transcription factor $C E B P B$ has been used to convert exocrine cell line AR42J into liver cells [43].

The timing of the introduction of $I P F 1$ was also important in our study as the cells from the 28-day monolayer culture showed the greatest ability to express beta cell markers, indicative of cooperation between transient plasticity and the induction of differentiation. The differentiation factors in ABNG [44-46] may also work by altering the gene expression profile. The composition of $\mathrm{ABNG}$ was the result of extensive analysis of the redifferentiation of partially dedifferentiated human islet cells [18] and the combination was essential in our system. The ABNG cocktail probably provides a balance between survival and stress signals to the cells. A similar phenomenon of environmental factors determining phenotype was observed in rat exocrine cells, as they could express markers of hepatocytes [47] or beta cells [16] under different conditions. Our protocol depended heavily on the in vivo environment, as no insulin protein was detectable until the cells were implanted into the diabetic mice. The hyperglycaemic in vivo environment and close contact with host cells may have contributed to the differentiation of cells into mature beta cells, although the exact mechanism is not yet fully understood. The slow reduction in plasma glucose in the diabetic mice following transplantation suggests the presence of a maturation process before the cells became fully glucose-responsive. Thus, the transdifferentiation of pancreatic non-endocrine cells into endocrine cells required interplay among complex factors, including transient plasticity, the ectopic expression of Ipf 1 , and the in vitro and in vivo environments. The origin of insulin-producing cells remains uncertain as the rapid phenotypic changes during culture made it difficult to identify the origin of the insulin-producing cells in our system. We have therefore attributed it to the non-endocrine cells as a whole. For reasons discussed above, we do not think the insulin-secreting cells came from a residuum of beta cells in the original cell preparation, although we cannot discount this absolutely.

Ultimately, as shown by the human C-peptide data and the glucose profiles in the intraperitoneal glucose tolerance tests, our protocol resulted in cells that were glucose-responsive, an important criterion for insulin-secreting cells for eventual human use. The culture system we describe is therefore a useful model in which to analyse the underlying molecular mechanisms of the transdifferentiation of human 
non-endocrine cells to mature, functional endocrine cells, including beta cells, and has the potential to be developed further to generate glucose-responsive insulin-producing cells in large quantity for clinical use.

Acknowledgements We thank Ms H. Mandefield, the transplantation coordinators of South-Thames and King's College Hospital, and relatives of the organ donors for human pancreases. We thank Professors A. McGregor, King's College GKT Medical School, King's College London and J. Price, Institute of Psychiatry, King's College London, for critical reading of the manuscript and their invaluable comments. We thank Dr J. Jones for insulin and human C-peptide analysis, and Dr M. Arno, at the Genomics Centre, School of Life Sciences, King's College London, for his assistance in the real-time PCR experiments. This work was supported by a research grant from Dixons Charitable Trust, UK, and the King's College Hospital Charitable Trust.

Duality of Interest

The authors declare that they have no financial interest in this study. The funding bodies do not have a role in collecting, analysing or publishing the data in this study.

\section{References}

1. Arias AE, Bendayan M (1993) Differentiation of pancreatic acinar cells into duct-like cells in vitro. Lab Invest 69:518-530

2. De Lisle RC, Logsdon CD (1990) Pancreatic acinar cells in culture: expression of acinar and ductal antigens in a growthrelated manner. Eur J Cell Biol 51:64-75

3. Hall PA, Lemoine NR (1992) Rapid acinar to ductal transdifferentiation in cultured human exocrine pancreas. J Pathol 166:97-103

4. Edlund H (1999) Pancreas: how to get there from the gut? Curr Opin Cell Biol 11:663-668

5. Edlund H (1998) Transcribing pancreas. Diabetes 47:18171823

6. St-Onge L, Wehr R, Gruss P (1999) Pancreas development and diabetes. Curr Opin Genet 9:295-300

7. von Schonfeld J, Goebell H, Muller MK (1994) The isletacinar axis of the pancreas. Int J Pancreatol 16:131-140

8. Githens S, Schexnayder JA, Moses RL, Denning GM, Smith JJ, Frazier ML (1994) Mouse pancreatic acinar/ductular tissue gives rise to epithelial cultures that are morphologically, biochemically, and functionally indistinguishable from interlobular duct cell cultures. In Vitro Cell Dev Biol Anim 30A:622-635

9. Kerr-Conte J, Pattou F, Lecomte-Houcke M et al (1996) Ductal cyst formation in collagen-embedded adult human islet preparations. A means to the reproduction of nesidioblastosis in vitro. Diabetes 45:1108-1114

10. Rooman I, Heremans Y, Heimberg H, Bouwens L (2000) Modulation of rat pancreatic acinoductal transdifferentiation and expression of PDX-1 in vitro. Diabetologia 43:907-914

11. Gmyr V, Kerr-Conte J, Belaich S et al (2000) Adult human cytokeratin 19-positive cells reexpress insulin promoter factor 1 in vitro: further evidence for pluripotent pancreatic stem cells in humans. Diabetes 49:1671-1680

12. Miller CP, McGehee RE Jr, Habener JF (1994) IDX-1: a new homeodomain transcription factor expressed in rat pancreatic islets and duodenum that transactivates the somatostatin gene. EMBO J 13:1145-1156

13. Bonner-Weir S, Taneja M, Weir GC et al (2000) In vitro cultivation of human islets from expanded ductal tissue. Proc Natl Acad Sci U S A 97:7999-8004

14. Gao R, Ustinov J, Pulkkinen MA, Lundin K, Korsgren O, Otonkoski T (2003) Characterization of endocrine progenitor cells and critical factors for their differentiation in human adult pancreatic cell culture. Diabetes 52:2007-2015
15. Heremans Y, Van De Casteele M, in't Veld P et al (2002) Recapitulation of embryonic neuroendocrine differentiation in adult human pancreatic duct cells expressing neurogenin 3. J Cell Biol 159:303-312

16. Lardon J, Huyens N, Rooman I, Bouwens L (2004) Exocrine cell transdifferentiation in dexamethasone-treated rat pancreas. Virchows Arch 444:61-65

17. Huang GC, Zhao M, Jones P et al (2004) The development of new density gradient media for purifying human islets and islet quality assessments. Transplantation 77:143-145

18. Zhao M, Christie MR, Heaton N, George S, Amiel S, Huang GC (2002) Amelioration of streptozotocin-induced diabetes in mice using human islet cells derived from long-term culture in vitro. Transplantation 73:1454-1460

19. Chakrabarti SK, James JC, Mirmira RG (2002) Quantitative assessment of gene targeting in vitro and in vivo by the pancreatic transcription factor, Pdx1. Importance of chromatin structure in directing promoter binding. J Biol Chem 277:13286-13293

20. Ponchel F, Toomes C, Bransfield K et al (2003) Real-time PCR based on SYBR-Green I fluorescence: an alternative to the TaqMan assay for a relative quantification of gene rearrangements, gene amplifications and micro gene deletions. BMC Biotechnol 13:18

21. Hall PA, Richards MA, Gregory WM, d'Ardenne AJ, Lister TA, Stansfeld AG (1988) The prognostic value of Ki67 immunostaining in non-Hodgkin's lymphoma. J Pathol 154:223-235

22. Campana D, Janossy G (1988) Proliferation of normal and malignant human immature lymphoid cells. Blood 71:1201-1210

23. SM Hobbs, (1997) Artificial DNA: bicistronic eukaryotic expression vector pIRES-N1 submitted to EMBL/GenBank/ DDBJ databases. AC no. Y11035

24. Elsner M, Tiedge M, Lenzen S (2003) Mechanism underlying resistance of human pancreatic beta cells against toxicity of streptozotocin and alloxan. Diabetologia 46:1713-1714

25. Kaltsas GA, Mukherjee JJ, Isidori A et al (2002) Treatment of advanced neuroendocrine tumours using combination chemotherapy with lomustine and 5-fluorouracil. Clin Endocrinol (Oxf) 57:169-183

26. Oberg K (2003) Diagnosis and treatment of carcinoid tumors. Expert Rev Anticancer Ther 3:863-877

27. Delaunoit T, Ducreux M, Boige V et al (2004) The doxorubicin-streptozotocin combination for the treatment of advanced well-differentiated pancreatic endocrine carcinoma; a judicious option? Eur J Cancer 40:515-520

28. Lendahl U, Zimmerman LB, McKay RD (1990) CNS stem cells express a new class of intermediate filament protein. Cell 60:585-595

29. Zulewski H, Abraham EJ, Gerlach MJ et al (2001) Multipotential nestin-positive stem cells isolated from adult pancreatic islets differentiate ex vivo into pancreatic endocrine, exocrine, and hepatic phenotypes. Diabetes 50:521-533

30. Selander L, Edlund H (2002) Nestin is expressed in mesenchymal and not epithelial cells of the developing mouse pancreas. Mech Dev 113:189-192

31. Piper K, Ball SG, Turnpenny LW, Brickwood S, Wilson DI, Hanley NA (2002) Beta-cell differentiation during human development does not rely on nestin-positive precursors: implications for stem cell-derived replacement therapy. Diabetologia 45:1045-1047

32. Humphrey RK, Bucay N, Beattie GM et al (2003) Characterization and isolation of promoter-defined nestin-positive cells from the human fetal pancreas. Diabetes 52:2519-2525

33. Lumelsky N, Blondel O, Laeng P, Velasco I, Ravin R, McKay R (2001) Differentiation of embryonic stem cells to insulin-secreting structures similar to pancreatic islets. Science 292:1389-1394

34. Kalluri R, Neilson EG (2003) Epithelial-mesenchymal transition and its implications for fibrosis. J Clin Invest 112:17761784

35. Jonsson J, Carlsson L, Edlund T, Edlund H (1994) Insulinpromoter-factor 1 is required for pancreas development in mice. Nature 371:606-609 
36. Ahlgren U, Jonsson J, Jonsson L, Simu K, Edlund H (1998) Beta-cell-specific inactivation of the mouse IpfI/PdxI gene results in loss of the beta-cell phenotype and maturity onset diabetes. Genes Dev 12:1763-1768

37. Weng J, Macfarlane WM, Lehto $M$ et al (2001) Functional consequences of mutations in the MODY4 gene (IPF1) and coexistence with MODY3 mutations. Diabetologia 44:249-258

38. Ferber S, Halkin A, Cohen $\mathrm{H}$ et al (2000) Pancreatic and duodenal homeobox gene 1 induces expression of insulin genes in liver and ameliorates streptozotocin-induced hyperglycemia. Nat Med 6:568-572

39. Horb ME, Shen CN, Tosh D, Slack JM (2003) Experimental conversion of liver to pancreas. Curr Biol 13:105-115

40. Ber I, Shternhall K, Perl S et al (2003) Functional, persistent, and extended liver to pancreas transdifferentiation. J Biol Chem 278:31950-1957

41. Koizumi M, Doi R, Toyoda E et al (2004) Hepatic regeneration and enforced $P D X-1$ expression accelerate transdifferentiation in liver. Surgery 136:449-457
42. Shen CN, Slack JM, Tosh D (2000) Molecular basis of transdifferentiation of pancreas to liver. Nat Cell Biol 2:879887

43. Tosh D, Shen CN, Slack JM (2002) Conversion of pancreatic cells to hepatocytes. Biochem Soc Trans 30:51-55

44. Florio P, Luisi S, Marchetti P et al (2000) Activin A stimulates insulin secretion in cultured human pancreatic islets. Endocrinol Invest 23:231-234

45. Otonkoski T, Beattie GM, Mally MI, Ricordi C, Hayek A (1993) Nicotinamide is a potent inducer of endocrine differentiation in cultured human fetal pancreatic cells. J Clin Invest 92:1459-1466

46. Mashima H, Ohnishi H, Wakabayashi K et al (1996) Betacellulin and activin A coordinately convert amylase-secreting pancreatic AR42J cells into insulin-secreting cells. J Clin Invest 97:16471654

47. Lardon J, De Breuck S, Rooman I et al (2004) Plasticity in the adult rat pancreas: transdifferentiation of exocrine to hepatocyte-like cells in primary culture. Hepatology 39:1499-1507 